\title{
Anesthesia Consideration for Renal Disease
}

\author{
Bhavna Gupta ${ }^{1 *}$, Lalit Gupta ${ }^{2}$ \\ ${ }^{I}$ Senior Resident, Department of Anesthesia and Critical Care, Maulana Azad Medical College and LokNayak \\ hospital, New Delhi, India \\ ${ }^{2}$ Assistant professor, Department of Anesthesia, Maulana Azad Medical College and LokNayak Hospital, New \\ Delhi, India
}

*Corresponding Author: Bhavna Gupta, Senior Resident, Department of Anesthesia and Critical Care, Maulana Azad Medical College and LokNayak hospital, New Delhi, India, Email: bhavna.Kakkar @gmail.com

Abstract: Anesthesia for renal disorders is described in detail in this review article.

\section{INTRODUCTION}

Kidneys is located in posterior abdominal wall, with $11^{\text {th }}$ and $12^{\text {th }}$ ribs and diaphragm placed posteriorly. It is $10 \mathrm{~cm}$ in length, $5 \mathrm{~cm}$ in width and $3 \mathrm{~cm}$ in thickness.

Sympathetic stimulation-is provided by preganglionic fibers T8-L1. Parasympathetic innervation is provided via vagus and s2-s4 segments that supply the ureters.

Nociceptive stimulation is via sympathetic innervation T10-L1 in kidneys and T10-L2 in ureters. Ureters receive sympathetic innervation via T10-L2 via aortico-renal and superior and inferior hypogastric plexus. Pain is therefore usually referred to the lower back, flank, ilioinguinal region and scrotum or labia.

Kidney is amongst the vital organs of the body. Its functions include filtration of plasma, maintaining water, osmolality, acid base balance and electrolytes balance. Production of urine begins with water and solute filtration from plasma flowing into the glomerulus via the afferent arteriole. Kidneys also secrete renin and regulates fluid and blood pressure. It also secretes erythropoietin. Conversion of 25 hydroxycholecalciferol to $1, \quad 25$ dihydroxycholecalciferol (vitamin D) is also mediated in proximal renal tubules. Kidneys are also involved in metabolism and excretion of many drugs.

Renal blood flow $(\mathrm{RBF})=20-25 \%$ of CO $(80 \%$ cortical nephrons, $20 \%$ medullary) with Auto regulation of RBF @ MAP of 80-180 mm Hg.
- Normal renal function is important for the excretion of anesthetics and medications, maintaining fluid and acid base balance, and regulating hemoglobin levels in the perioperative period.

- Renal disease is quite prevalent in patients presenting for surgery and is associated with increased likelihood of poor postoperative outcomes. Even mild renal dysfunction is associated with a more likely risk of postoperative complications.

The glomerular filtration rate (GFR) is a measure of glomerular function expressed as milliliters of plasma filtered per minute and is heavily influenced by arteriolar tone at points upstream (afferent) and downstream (efferent) from the glomerulus.

- Glomerular Filtration Rate is defined as volume of fluid which is filtered from the glomerular capillaries into bowman capsule per unit time. It is measured as milliliters per minute or $\mathrm{ml} / \mathrm{min}$. Normal range of GFR adjusted for body surface area is 100 $\mathrm{ml} / \mathrm{min} / 1.73 \mathrm{~m} 2$ in men and 120 $\mathrm{ml} / \mathrm{min} / 1.73 \mathrm{~m} 2$ in females younger than 40 years. GFR is $110 \mathrm{ml} / \mathrm{min} / 1.72 \mathrm{~m} 2$ in children until 2 years of age and it progressively decrease after that. After the age of 40 years, GFR progressively decrease by $0.4-1.2 \mathrm{ml} / \mathrm{min} /$ year. GFR is often used for classifying chronic Kidney Disease (CKD): (Table1) 
Table1. Classification of $C K D$ with respect to GFR

\begin{tabular}{|l|l|c|}
\hline Stage & Description & GFR(ml/min $\left./ 1.73 \mathrm{~m}^{2}\right)$ \\
\hline I & CKD with normal GFR but other renal damage (e.g. haematuria, proteinuria) & $>90$ \\
\hline II & Mild CKD and other kidney damage & $60-89$ \\
\hline III & Moderate CKD & $30-59$ \\
\hline IV & Severe CKD & $15-29$ \\
\hline V & Established ESRF & $\begin{array}{c}<\text { or on Renal } \\
\text { ReplacementTherapy }\end{array}$ \\
\hline
\end{tabular}

2. Clinical Assessment Of The Renal FUNCTION

A simple clinical assessment involves a set of

Table2. Different parameters to assess clinical status clinical tests. (Measures such as urine output correlate only poorly with perioperative renal function) (Table-2)

\begin{tabular}{|l|l|}
\hline Parameter & Assessment \\
\hline Serum Creatinine: & GFR should be assessed \\
\hline BUN & Not ideal because influenced by dehydration and postoperative catabolic states \\
\hline $\begin{array}{l}\text { Urine output }(<400 \\
\text { mL urine/24 hr) }\end{array}$ & $\begin{array}{l}\text { may reflect hypovolaemia or impending "prerenal" renal failure; perioperative renal } \\
\text { failure often develops in the absence of oliguria }\end{array}$ \\
\hline Urine specific gravity: & $>1.018$ implies preserved renal concentrating ability \\
\hline $\begin{array}{l}\text { Urinalysis and urine } \\
\text { characteristics }\end{array}$ & Inspection for cloudiness, color, odors \\
\hline BUN = blood urea nitrogen; GFR = glomerular filtration rate. \\
\hline
\end{tabular}

\section{Perioperative NePhrology}

\subsection{Acute Kidney Conditions}

It can be a result of many underlying conditions like:

- Acute kidney injury (AKI) is the preferred term for an acute deterioration in renal function. It is associated with a decline in glomerular filtration and results in an inability of the kidneys to excrete nitrogenous and other wastes. AKI frequently occurs in the setting of critical illness with multiple organ failure, and the mortality rate is alarmingly high $(\leq 90 \%)$.
- Prerenal azotemia is an increase in blood urea nitrogen associated with renal hypoperfusion or ischemia that has not yet caused renal parenchymal damage.

- Intrinsic AKI includes injury caused by ischemia, nephrotoxins, and renal parenchymal diseases.

- Postrenal AKI (Obstructive Uropathy). Downstream obstruction of the urinary collecting system is the least common pathway to established AKI, accounting for $<5 \%$ of cases.

- Nephrotoxins and Perioperative AKI (Table-3)

Table3. Types of Nephrotoxins

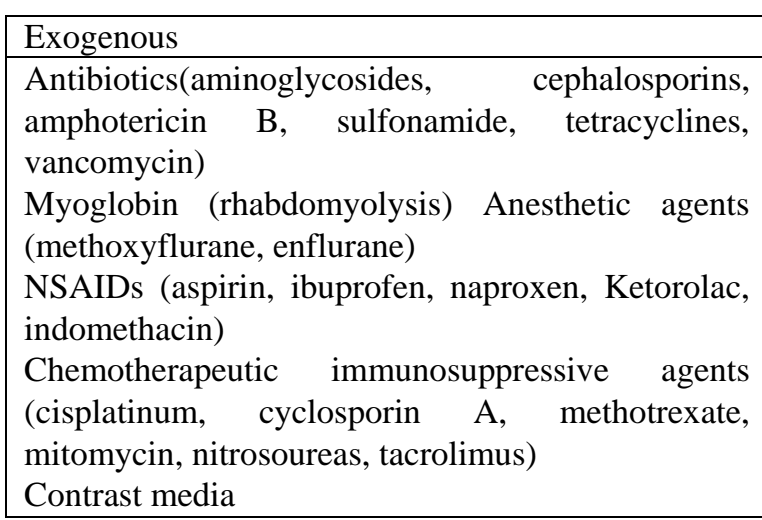

\subsection{Chronic Kidney Disease (CKD)}

These patients usually have GFRs below 25\% of normal. Patients with decreased renal reserve are often asymptomatic and frequently may not have elevated blood levels of creatinine or urea.
Endogenous

Calcium (hypercalcemia)

Uric acid (hyperuricemia and hyperuricemia)

Hemoglobin (hemolysis)

Bilirubin (obstructive jaundice)

Oxalate crystals

Paraproteins
- The uremic syndrome represents an extreme form of CRF, which occurs as the surviving nephron population and GFR decrease below $10 \%$ of normal. It results in an inability of the kidneys to perform their two major functions, regulation of the volume $(\mathrm{ECF})$ and excretion of waste products. 
- Water balance in ESRD becomes difficult to manage due to the decreased number of functioning nephrons. This results in failure both to conserve water and to excrete excess water. Such patients often require frequent or continuous dialysis.

- Life-threatening hyperkalemia may occur in patients with CKD because of slower-thannormal potassium clearance. Derangements in calcium, magnesium, and phosphorus metabolism are also commonly seen in patients with CKD.

- Metabolic acidosis occurs in two forms in ESRD (hyperchloremic, normal anion gap acidosis and a high anion gap acidosis caused by an inability to excrete titratable acids)

\section{Pre-Operative Assessment}

- Routine anesthetic assessment along with special attention to renal functions is made.

- Hypertension is commonly seen in chronic renal failure, because of renin angiotensin pathway. Accelerated ischemic heart disease and peripheral vascular disease are the consequences of the same.

- Proteinuria and hypoalbuminemia predispose to oedema. Pericarditis, autonomic and peripheral neuropathy is also commonly seen in chronic kidney disease.

- Urinalysis is a cheap, readily available, and informative laboratory test. Proteinuria greater than $150 \mathrm{mg} /$ day indicates severe glomerular damage and glycosuria is indicative of diabetes mellitus.

- A complete blood count may reveal anemia of normocytic normochromic type of anemia, causes of the same include excessive hematuria, reduced production of erythropoietin by failing kidneys.

- Serum electrolytes although may remain normal until severe renal disease should be measured.

- Determination of arterial blood gases may reveal metabolic acidosis in severe renal failure due to impaired excretion of acid by the failing kidneys

- Chest X ray and ECG may be required depending upon chronicity of disease and associated comorbidities.

- Patients should be optimized in preoperative period, hypertension should be managed with anti-hypertensives, antibiotic coverage for urinary infections. Routine transfusion is not recommended in chronic kidney disease and may predispose to CHF. Electrolytes should be corrected appropriately and dialysis may be needed in severe renal failure. Premedicants may be necessary and anatacids prophylaxis may be considered.

5. Pharmacology of Drug in Renal DISEASE

- Termination of drug action is mediated via redistribution and metabolism, and is not dependent on renal excretion. Metabolism leads to inactive form of parent drug and are water soluble, therefore is excreted in urine. Accumulation of these products due to impaired renal excretion is not harmful. In patients with $\mathrm{CKD}$, the effect of altered clearance, the production and accumulation of active metabolites, and the risk of aggravating pre-existing kidney disease on drug administration must be considered.

- Dose adjustment is not usually necessary until the GFR is $<50 \mathrm{ml} / \mathrm{min} / 1.73 \mathrm{~m}^{2}$

\section{Pharmacokinetics}

- Absorption - affected by delayed gastric emptying

- Distribution - volume of distribution is increased or decreased depending on total body water, Protein binding \& time since last dialysis

- Elimination - prolonged half life for drugs with renal elimination, e.g. Vecuronium

\subsection{Local Anaesthetics (LA)}

- L.A. has two plasma protein binding sites: a high affinity, low capacity site on AAG ( $\alpha 1$ acid glycoprotein) and a low affinity, high capacity site on albumin.

- The albumin binding site becomes increasingly important as the plasma concentration of the local anaesthetic increases.

- Metabolic acidosis increases the percentage of unbound drug and this effect is more pronounced with bupivacaine.

- Maximum dose to be decreased by $25 \%$ due to decreased protein binding and lower CNS seizure threshold in ESRD. 


\subsection{Inhalation Agents}

- "All inhalation agents are bio-transformed to non-volatile products of metabolism which are eliminated by kidney, but reversal of CNS effect depends upon pulmonary excretion".
- All inhalation agents cause transient reversible $\downarrow$ of GFR, Renal blood flow, Urine output and renal auto regulation(Table-4)

Table4.Types of Inhalational agents with nephrotoxic potential

\begin{tabular}{|l|l|l|}
\hline \multicolumn{3}{|c|}{ Inhalation Agents } \\
\hline Halothane & Inorganic fluoride levels are less:1-2 $\mu \mathrm{M} / \mathrm{L}$ & No Nephrotoxicity \\
\hline Isoflurane & Inorganic fluoride levels are less: 3-5 $\mu \mathrm{M} / \mathrm{L}$ & No Nephrotoxicity \\
\hline Desflurane & $\begin{array}{l}\text { Inorganic fluoride levels are very less, }<1 \mu \mathrm{M} / \mathrm{L} \text { after 1MAC-hr; } \\
\text { highly stable \& resists degradation by soda-lime \& liver }\end{array}$ & No Nephrotoxicity \\
\hline Sevoflurane & $\begin{array}{l}\text { Inorganic fluoride levels are less but not stable 50 } \mu \mathrm{M} / \mathrm{L} \\
\text { prolonged use; degraded by soda-lime to compound A \& } \\
\text { undergoes liver metabolism }\end{array}$ & $\begin{array}{l}\text { Compound A is } \\
\text { nephrotoxic after }\end{array}$ \\
\hline Enflurane & $\begin{array}{l}\text { Bio transformed to inorganic fluoride levels after prolonged use (> } \\
\text { 4hrs) }\end{array}$ & $\begin{array}{l}\text { Nephrotoxic } \\
\text { prolonged use }\end{array}$ \\
\hline Methoxyflurane & Bio transformed to high inorganic fluoride levels & Highly nephrotoxic \\
\hline
\end{tabular}

\subsection{Intravenous agents}

The induction agents of choice in renal disease are Propofol and Etomidate as they are

\begin{tabular}{|c|c|c|}
\hline Thiopentone & $\begin{array}{l}\text { CNS effect reversed by redistribution \& hepatic } \\
\text { metabolism, also } 80 \% \text { protein bound, } \downarrow \text { albumin in } \\
\text { uremia } \rightarrow \uparrow \text { free drug, more free un-ionised drug in } \\
\text { acidosis, also } \uparrow \mathrm{Vd}\end{array}$ & $\begin{array}{l}\text { Metabol. unchanged } \\
\text { Rate of admin. should be slow } \\
\text { Used in } \downarrow \text { dose } \\
\text { ( } \downarrow \text { protein binding) }\end{array}$ \\
\hline Propofol & $\begin{array}{l}\uparrow \mathrm{Vd} \text { but clearance } \& \mathrm{t}_{1 / 2} \text { unaltered, Metabolized by } \\
\text { liver }\end{array}$ & $\begin{array}{l}\text { No adverse effect, time taken to } \\
\text { awake after infusion } \downarrow\end{array}$ \\
\hline Etomidate & Metabolised by liver, partial renal excretion & No adverse effect \\
\hline $\begin{array}{l}\text { Benzodiazepines } \\
\text { (BZD) }\end{array}$ & $\begin{array}{l}\text { Metabolised in liver \& excreted by kidney, Longer } \\
\text { acting BZD accumulate, } \\
\uparrow \text { duration of action }\end{array}$ & $\uparrow$ Interval or $\downarrow$ dose \\
\hline Ketamine & $\begin{array}{l}\text { Pharmacokinetics minimally changed } \\
\text { Hepatic metabolites may depend on renal excretion } \\
\text { and can potentially accumulate }\end{array}$ & Used in $\downarrow$ dose \\
\hline
\end{tabular}

\subsection{Muscle Relaxants}

The increased Volume of distribution in renal disease necessitates the larger initial dose to metabolized by liver and their excretion is not renal dependent. (Table-5) produce neuromuscular blockade but due to reduced metabolism and excretion of drugs, maintenance dose is decreased under neuromuscular monitoring (Table-6).

Table6. Types of muscle relaxants with their nephrotoxic potential

\begin{tabular}{|l|l|l|}
\hline Succinylcholine & $\begin{array}{l}\text { Metabolised by psedocholinesterase to non toxic products } \\
\text { which are excreted by kidney, } \uparrow \text { duration in ESRD, also } \\
\downarrow \text { psedocholinesterase in uremia, Associated with rapid } \\
\text { transient } \uparrow \mathrm{K}^{+}(0.5 \mathrm{mEq} / \mathrm{L})\end{array}$ & $\begin{array}{l}\text { Longer block in ESRD \& } \\
\text { uremia,Cautiously used in } \\
\text { hyperkalemia }\end{array}$ \\
\hline Atracurium & $\begin{array}{l}\text { Degraded by enzymatic ester hydrolysis \& non enzymatic } \\
\text { alkaline degradation (Hoffmann elimination) to inactive } \\
\text { products }\end{array}$ & $\begin{array}{l}\text { Not dependent on renal } \\
\text { elimination }\end{array}$ \\
\hline Mivacurium & Metabolised by plasma psedocholinesterase & Longer block in ESRD \\
\hline Cis-atracurium & $77 \%$ hoffmann elimination \& $16 \%$ renal elimination & Mild effect \\
\hline Vecuronium & $30 \%$ renal elimination & Prolonged duration \\
\hline Rocuronium & $\uparrow V d, 30 \%$ renal elimination, No change in clearance & Prolonged duration \\
\hline Pancuronium & $\begin{array}{l}40-50 \% \text { renal excretion, partly via less active 3-OH } \\
\text { pancuronium- renal excretion }\end{array}$ & Prolonged duration \\
\hline & \begin{tabular}{l} 
Increased; $\downarrow$ decreased; Vd volume of distribution \\
\hline
\end{tabular}
\end{tabular}




\subsection{Opioids}

- Opioids have no direct toxic effects on the kidney (Table-7).

- They do, however, have an antidiuretic effect, and they may cause urinary retention.

- Tramadol: $30 \%$ of tramadol is excreted unchanged in the urine. O-Demethyl tramadol is an active metabolite which is excreted by the kidneys. Uraemia is associated with a lowered seizure threshold, and tramadol may be epileptogenic in these circumstances.

- Codeine and dihydrocodeine are also best avoided as their elimination half-life is significantly prolonged, and conventional doses have resulted in central nervous system depression.

Table7. Different Types of opioids agents with their nephrotoxic potential

\begin{tabular}{|l|l|l|l|}
\hline \multicolumn{5}{|c|}{ Opioids } \\
\hline Morphine & $\begin{array}{l}\text { Conjugated to M-3-G, M-6-G,active } \\
\text { metabolite, respiratory depression }\end{array}$ & $\begin{array}{l}\text { Active metabolite has renal } \\
\text { elimination, 40\% } \\
\text { occurs in kidney } \\
\text { conjugation }\end{array}$ & $\begin{array}{l}\text { Dose adjustment } \\
\text { required }\end{array}$ \\
\hline $\begin{array}{l}\text { Meperidine } \\
\text { (Pethidine) }\end{array}$ & $\begin{array}{l}\text { Normeperidine (main metabolite), } \\
\text { CNS toxicity }\end{array}$ & $\begin{array}{l}\text { Active metabolite has renal } \\
\text { elimination }\end{array}$ & $\begin{array}{l}\text { Dose adjustment } \\
\text { required }\end{array}$ \\
\hline Fentanyl & $\downarrow$ Plasma protein binding, $\uparrow$ free drug & $\begin{array}{l}\text { Clearance not altered (7\% renal safe } \\
\text { metabolism) }\end{array}$ & safe \\
\hline Sufentanil & $\downarrow$ Plasma protein binding, $\uparrow$ free drug & Clearance not altered & safe \\
\hline Alfentanil & $\downarrow$ Initial vol of distribution, $\uparrow$ free drug & Clearance not altered & safe \\
\hline Remifentanil & No change (ester hydrolysis ) & Clearance not altered & \\
\hline
\end{tabular}

6. ANESTHESIA

\subsection{Intra-operative}

- General anesthesia with positive pressure ventilation using muscle relaxation is recommended for open or laparoscopic renal surgery.

- Endotracheal intubation is used as there is increase in abdominal pressure owing to positioning of the patient and laparoscopic surgery

- Rapid sequence intubation is preferred in patients with gastropathy owing to chronic renal failure. Induction of anesthesia may be achieved with intravenous and inhalational agents. Maintenance of anesthesia is achieved with inhalational agents.

- Atracurium is the preferred muscle relaxant as it is metabolized by Hoffman degradation.

- Large bore intravenous line is required as there may be sudden risk of bleeding. Limb with arteriovenous fistula must not be used for intravenous infusions.

\subsection{Monitoring}

- Routine standard monitoring is must. Patients with end stage disease may require central venous pressure monitored fluid administration. Temperature monitoring is required as renal surgery may take many hours. Warm intravenous fluids, warming blanket may be used.

\subsection{Fluid balance}

- Patients may be dehydrated as they are given bowel preparation and may be on dialysis, particularly in old age individuals.

- Appropriate fluid resuscitation is required in patients with signs and symptoms of dehydration so as to avoid sudden hypotension at induction.

- Crystalloids are used for maintenance and third space losses. Potassium containing fluids are avoided in patients with impaired renal function to avoid hyperkalemia. Colloids and packed red blood cells are reserved for blood loss replacement.

- Aim of urine output should be $0.5-1 \mathrm{ml} / \mathrm{kg} / \mathrm{h}$ in patients with normal renal function. Dilaysis may be reserved in post operative period if there is fluid overload or chances of patients going into overload.

\subsection{Renal Protection}

- Various measures can be taken to protect kidney function in ongoing surgery. Although surgery is a major factor, other contributory factors should also be avoided, which include dehydration, sepsis, hypotension and nephrotoxic drugs

- Administration of fluids, dopamine, diuretics, calcium channel blockers, and angiotensin coverting enzyme inhibitors may be required to protect from renal damage. However there are conflicting 
evidence if any of these interventions protect kidney from damage.

\subsection{Post-Operative Pain Relief}

There can be significant pain especially in open approach to kidney. Multimodal analgesia is required for early mobilization and to reduce incidence of post-operative pulmonary complications. Epidural analgesia should be a norm unless contraindicated. Regional analgesia is contraindicated in presence of coagulopathy, thrombocytopenia, anticoagulation, or recent hemodialysis. Fentanyl and other short acting opioids are useful as they are largely metabolized in liver. Non-steroidal antiinflammatory drugs are contra indicated because of their nephrotoxic potential. Paracetamol is a safe drug and is a good adjuvant analgesic.

\section{SUMMARY}

Patients with renal impairment or insufficiency are a challenge to attending anesthesiologists. Adequate fluid of management, maintenance of normovolumia, and avoidance of both hypotension and hypertension is required for successful prevention of further renal damage. It is imperative that the anesthesiologists dealing with such patients not only understand the management of these patients but also intervene to prevent further renal injury during the perioperative period.

\section{REFERENCES}

[1] Malhotra V and Diwan S. Anesthesia for the Renal and Genitourinary Systems. In: Miller RD (Ed) Anesthesia. (5th Ed) Chapter 53; pg 1934-1959. Churchill Livingstone, Philadelphia.

[2] Butterworth JF, Mackey DC, Wasnick JD. Morgan and Mikhail's Clinical Anaesthesiology $5^{\text {th }}$ Edition. Ch 29 pg $631-$ 652 (Renal Physiology and Anaesthesia) \&Ch $30 \mathrm{pg} 653-670$ (Anaesthesia for patients with kidney disease) 2013 The McGraw Hill Companies, Inc.

[3] Eilers H, Liu KD, Gruber A, Niemann CU. Chronic kidney disease: implications for the perioperative period. Minerva Anestesiologica 2010; 76:725 - 736 .

[4] Wallace K. Renal Physiology. Update in Anaesthesia.

Citation: Bhavna Gupta, Lalit Gupta. Anesthesia Consideration for Renal Disease. ARC Journal of Anesthesiology. 2018;3(1):9-14. DOI: dx.doi.org/10.20431/2455-9792.0301003.

Copyright: (C) 2018 Authors. This is an open-access article distributed under the terms of the Creative Commons Attribution License, which permits unrestricted use, distribution, and reproduction in any medium, provided the original author and source are credited. 